\title{
Copycat Suicide Induced by Entertainment Celebrity Suicides in South Korea
}

\author{
Soo Ah Jang ${ }^{1}$, Ji Min Sung ${ }^{2}$, Jin Young Park ${ }^{1}$, and Woo Taek Jeon ${ }^{1 凶}$ \\ ${ }^{1}$ Department of Psychiatry and Institute of Behavioral Science in Medicine, Yonsei University College of Medicine, Seoul, Republic of Korea \\ ${ }^{2}$ Division of Cardiology, Yonsei Cardiovascular Center, Yonsei University College of Medicine, Seoul, Republic of Korea
}

Objective Throughout the past several years, there have been a number of entertainment celebrity suicides in South Korea. The aim of this study was to investigate the clustering of suicides following celebrities' suicides in South Korea from 2005 to 2008, particularly according to certain characteristics.

Methods Seven celebrity suicides were examined and defined using the Korean Integrated Newspaper Database System (KINDS) and from these, we considered four affected periods occurring 28 days after each celebrity's suicide. A Poisson time-series autoregression model was used to estimate the relative risk of the total suicide number for each affected period from 2005 to 2008. Logistic regression analysis was performed to investigate whether there were specific increases in the numbers of suicides in subgroups matching each celebrity.

Results There were significant increases in the risk of suicide during the affected periods. Remarkable increases were found in the subgroups matching each celebrity, especially in the group in which all factors (sex, age, and method) were similar.

Conclusion This study provides confirmation that a significant copycat effect was induced by these celebrities' suicides, especially among people who identified more with the celebrities. This implies that countermeasures for upright media coverage of celebrity suicides should be discussed and practiced properly in South Korea.

Psychiatry Investig 2016;13(1):74-81

Key Words Suicide, Risk factors, Imitative behavior, Mass media, Republic of Korea.

\section{INTRODUCTION}

Media reports of suicide induce suicide clusters in populations that come into contact with the report. ${ }^{1}$ This phenomenon is known as imitation, and is specifically referred to as "copycat suicide". ${ }^{2}$ Celebrity suicides are known to induce more of a copycat effect than suicides of the general population, as they might cause a greater impulse to imitate. Among the various types of celebrities, entertainment celebrities especially were found to generate a more significant copycat effect. ${ }^{3}$

There has been a radical increase in the suicide rate in South Korea since 1997 when the economic crisis occurred. ${ }^{4}$ The suicide rate increased from 11.8 (per 100,000 people) in 1995 to 28.9 in 2012, with suicide rising from the ninth lead-

Received: April 15, 2015 Revised: July 19, 2015

Accepted: July 30, 2015 Available online: October 19, 2015

$\triangle$ Correspondence: Woo Taek Jeon, MD, PhD

Department of Psychiatry and Institute of Behavioral Science in Medicine, Yonsei University College of Medicine, 50-1 Yonsei-ro, Seodaemun-gu, Seoul 03722, Republic of Korea

Tel: +82-2-2228-2510, Fax: +82-2-364-5450, E-mail: wtjeon@yuhs.ac

(c) This is an Open Access article distributed under the terms of the Creative Commons Attribution Non-Commercial License (http://creativecommons.org/licenses/by$\mathrm{nc} / 3.0$ ) which permits unrestricted non-commercial use, distribution, and reproduction in any medium, provided the original work is properly cited. ing cause of death to the fourth leading cause of death, ${ }^{5}$ and the highest among OECD countries. ${ }^{6}$ During this time, numerous celebrity suicides, notably entertainment celebrity suicides, occurred in quick succession. ${ }^{7}$ It is thought that these were followed by many copycat suicides, and that this phenomenon contributed to the increasing suicide rate. Celebrity suicide is known to affect mostly females, ${ }^{2}$ and although the main suicidal group in South Korea is elderly males, ${ }^{4}$ the copycat effect is presumed to be an important factor in the female population.

There have been several studies that have investigated the copycat effect of celebrity suicides in South Korea. Previous studies demonstrated a copycat effect by analyzing suicide data after one or two celebrity suicides, examining suicide attempts in emergency departments and demonstrating the correlation of media coverage with overall changes of suicide number. ${ }^{8-10}$

Notably, certain studies have investigated the copycat effect in South Korea by exploring characteristics of vulnerable subgroups. In Lee et al.s study, ${ }^{10}$ which examined quantitative and qualitative aspects of media reports after celebrity suicides, all subgroups except for young males $(\leq 29)$ were found 
to be influenced by actress C.J.s suicide in 2008. Widening the covered period and including more celebrities, Myung et al. ${ }^{11}$ found that the people who were females, $20-30$ years of age, and preferred to die by hanging were more likely to commit suicides after celebrity suicide, especially when the copycat effect was high. In addition, they identified significant associations of characteristics between the celebrities and suicide victims of the copycat effect. Based on these previous results on vulnerable populations, we particularly aimed to explore the copycat effect in subgroups matching the celebrities in regard to sex, age, and method of suicide; therefore, we focused on these populations.

To pursue these aims, we intended to answer two specific questions. First, we aimed to determine whether the copycat effect existed after each case of celebrity suicide. Second, we attempted to identify whether copycat suicides were more frequently induced among people who identified more with the celebrities. We compiled a list of entertainment celebrities who committed suicide from 2005 to 2008 and then investigated whether there were copycat effects during the affected periods of the celebrity suicides and whether the copycat effects were higher in the subgroups matching the celebrities based on the sex, age, and method of suicide of the suicide committers.

\section{METHODS}

\section{Suicides of celebrities}

We searched and examined "Mediagaon" of the Korean Integrated Newspaper Database System (KINDS) operated by the Korean Press Foundation (KPF), using the search terms "suicide", and "entertainment celebrity suicide" within a limited time period (2005-2008). We defined entertainment celebrity suicide as meeting two conditions. First, an entertainment celebrity was defined as a person who performed an entertainment activity and was recognized in pop culture. Second, an entertainment celebrity suicide was required to have been reported on average more than three times each in six different media outlets (five newspapers: Kukmin Ilbo, Kyunghyang Sinmun, Hankyoreh Sinmun, Maeil Economy, Korean Economy; one internet site: Ohmynews). Ultimately, we identified seven entertainment celebrity suicides from 2005 to 2008. All celebrity suicides were reported on the same day as the suicide, as soon as they were disclosed.

\section{Suicide data}

We obtained micro-data for the number of suicides from 2005-2008 from Statistics Korea (http://mdss.kostat.go.kr). Micro-data were collected from individual suicide cases and included the date, age, sex, and method of suicide for each case, as classified according to the International Classification of Disease (ICD) 10. To infer overall tendency, we created a graph with time-series data for suicide numbers by month, sex, age ( $\leq 19,20-29,30-39,40-49, \geq 50)$ and method (hanging, carbon monoxide poisoning, and others) from 20052008.

\section{Adjusted data}

To adjust unemployment rate, we obtained monthly unemployment rates from Statistics Korea to adjust for confounding effects based on socio-environmental factors. ${ }^{12}$ In our analysis, the daily unemployment rate (\%) was considered as identical to the rate for the month. The unemployment rate was calculated as the number of unemployed people divided by the sum of unemployed and employed people.

\section{Affected periods}

We defined the affected periods of each celebrity suicide as 28 days after each suicide, according to preceding studies. ${ }^{13,14}$ However, several of these affected periods overlapped; thus, we created only four periods. In 2005, there was only one case, and we identified this as Period 1. In 2007, there were two cases, and second case occurred 20 days after first case. We set Period 2 as the day of the first case to 28 days after the second case (total 48 days) in 2007. In 2008, there were four cases that occurred within one month of each other. However, the second case occurred 23 days after the first case, and the characteristics of the suicides were different. Thus, we separated these two cases, setting Period 3 as the day of the first case to the day before the second case (24 days) in 2008. The third and fourth cases occurred within one week after the second case. Given that the popularities of the third and fourth celebrities were much lower than that of the second celebrity, it seemed that copycat suicides during that period would be mostly due to the second case. Therefore, we set Period 4 as the day of the second case to 28 days after the second case.

\section{Statistical analyses}

First, taking into consideration that this study collected time series data and that outcome variables would be count data, a Poisson time-series autoregression model was used to estimate the relative suicide risk of total suicide number for the affected period from 2005 to $2008 .^{15-17}$ Second, a logistic regression analysis was performed to obtain the odds ratio of suicide numbers in subgroups based on sex, age, and suicide method and matching each celebrity who committed suicide. Considering that previous studies had concluded that seasonal and monthly variations had a considerable impact on suicide rates, ${ }^{18}$ the variables were adjusted accordingly in all analyses. In addition, we adjusted the unemployment rate of the previous month, which is an identified risk factor of suicide from 
earlier studies. ${ }^{19,20}$ In a logistic regression analysis, we additionally adjusted sex, age, and method. SAS version 9.2 (SAS Institute, Inc, Cary, NC, USA) was used for all analyses. A p-value of less than 0.05 was considered statistically significant.

\section{RESULTS}

\section{Suicides of celebrities}

There were seven entertainment celebrities who committed suicide from 2005 to 2008 (Table 1). Five were female, and all were younger than 40 years old. With the exception of A.J., who was poisoned by carbon monoxide gas in a car, all others hanged themselves at home. In 2006, there were no celebrity suicides; however, in 2008, four celebrities committed suicide in about one month. The suicides of A.J. and C.J. were especially interrelated. It was inferred that the reason for A.J.'s suicide was that he was harassed by a private moneylender. After his death, the public suspected C.J. as the moneylender, and she was cruelly blamed on the internet. After about one month, she also committed suicide. Although this might not be a unique cause of suicide, public blame could have been one of the driving forces in C.J.s death. ${ }^{21}$ We thus speculate that the public and celebrities might influence each other.

C.C. and K.J., who committed suicide immediately after C.J.'s death, were not very popular, and many people did not even know of their existence. However, they were included as celebrities as their suicides were reported more than three times each by major media outlets. These celebrities were reported on more after their suicide than before. From this, we can infer two things. First, most copycat suicides during that period were influenced by C.J.: therefore, C.C. and K.J. fell into the category of victims of the copycat suicide effect following C.J.s death. Second, despite this fact, their subsequent suicides were reported by media and contributed to further cluster suicides. Considering that C.C. and K.J. were less popular than C.J. and that their demographic characteristics were different from C.J.'s, which would complicate the analysis of the subgroups, we excluded the effects of C.C. and K.J. from this study.

\section{Increased number of suicides}

Figure 1 shows a radical increase in the number of suicides after celebrity suicides. According to Figure 2, which is a timeseries graph of the numbers of suicides by sex and age group, we deduced that men over the age of 50, who comprised the majority of total suicides, were mostly affected by monthly and seasonal changes rather than by celebrity suicides. We also inferred that females in their twenties and thirties were mainly affected by celebrity suicides.

Table 2 shows the relative risk of suicide during each affected period compared to unaffected period which is the remainder of 2005-2008. There was a $29.7 \%$ (95\% CI: $18.4-$ $42.1 \%$ ) increase in the risk of suicide in Period 1, affected by L.E.; a 42.2\% (95\% CI: 32.5-52.5\%) increase in Period 2, affected by U.N. and J.D.; a 14.6\% (95\% CI: 3.7-26.6\%) increase in Period 3, affected by A.J.; and a 95.4\% (95\% CI: 78.8-113.4\%) increase in Period 4, affected by C.J.

Table 3 shows a comparison of the odds ratios of the numbers of suicides in same subgroup according to the matching sex, age, and method of suicide of each celebrity during the affected period as compared to the unaffected period. Except for Period 3, which showed insignificant odds ratios in same sex (male) and age (30-39) groups, all other periods showed significant increases in odds ratios in all matching subgroups. There was an especially increased risk of suicide in the subgroups in which all factors (sex, age, and method) matched with the celebrity: Period 1, 143.8\% (95\% CI: 96.6-213.6\%); Period 2, 287.3\% (95\% CI: 221.7-366.4\%); Period 3, 294.8\%

Table 1. Celebrity suicide characteristics (South Korea, 2005-2008)

\begin{tabular}{|c|c|c|c|c|c|c|c|}
\hline Period category & Name* & Occupation & Age at death & Gender & Location & Date & $\begin{array}{c}\text { Method } \\
\text { (ICD-10 code) }\end{array}$ \\
\hline $\begin{array}{l}\text { Period } 1 \\
(2005 / 02 / 22-2005 / 03 / 21)\end{array}$ & L.E. & Actress & 24 & $\mathrm{~F}$ & Home & 2005-Feb-22 & Hanging (X70) \\
\hline Period 2 & U.N. & Singer & 25 & $\mathrm{~F}$ & Home & 2007-Jan-21 & Hanging (X70) \\
\hline$(2007 / 01 / 21-2007 / 03 / 09)$ & J.D & Actress & 26 & $\mathrm{~F}$ & Friends' home & 2007-Feb-10 & Hanging (X70) \\
\hline $\begin{array}{l}\text { Period } 3 \\
(2008 / 09 / 08-2008 / 10 / 01)\end{array}$ & A.J. & Actor & 36 & M & Car & 2008-Sep-08 & $\begin{array}{l}\text { Carbon } \\
\text { Monoxide (CO) } \\
\text { Poisoning (X67) }\end{array}$ \\
\hline \multirow{3}{*}{$\begin{array}{l}\text { Period } 4 \\
(2008 / 10 / 02-2008 / 10 / 29)\end{array}$} & C.J. & Actress & 39 & $\mathrm{~F}$ & Home & 2008-Oct-02 & Hanging (X70) \\
\hline & C.C. & Entertainer & 26 & $\mathrm{M}^{\dagger}$ & Home & 2008-Oct-03 & Hanging (X70) \\
\hline & K.J. & Model & 22 & M & Home & 2008-Oct-07 & Hanging (X70) \\
\hline
\end{tabular}

${ }^{*}$ names are marked as initials, ${ }^{\dagger}$ C.C was transgender but he was recorded as a male in ID. ICD: International Classification of Disease 


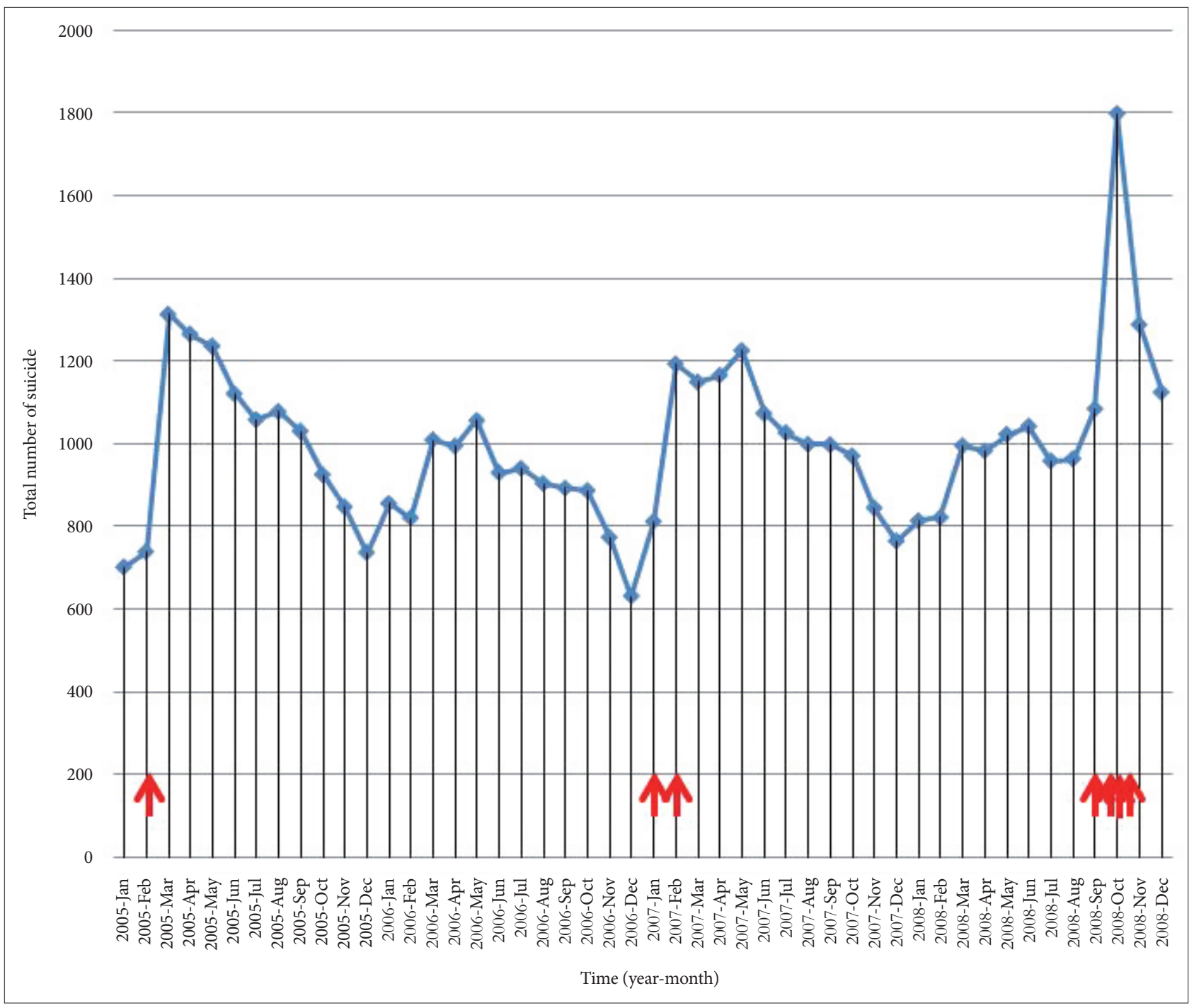

Figure 1. Monthly total number of suicides (South Korea, 2005-2008). Arrows represent points of celebrity suicides.

(95\% CI: 103.7-665.0\%); Period 4, 155.4\% (95\% CI: 110.6209.7\%).

\section{DISCUSSION}

There were seven cases of celebrity suicides from 2005 to 2008 in South Korea. The results of this analysis show that celebrity suicides significantly influenced the number of suicides immediately post-event. Entertainment celebrity suicides caused an increase in the number of suicides, especially in people of the same gender and age group, and many of them even used the same method. Therefore, it is clear that the copycat suicide phenomenon existed following celebrities' suicides in Korea.

There are several points worth noting in our results. First, A.J's suicide induced a relatively lower increase in the number of suicides in Period 3 than in other periods (Table 2).
Moreover, in that period, the odds ratios for those of the same sex (male) and age (30-39 years old) were not meaningfully high. A.J's suicide differed from those of the other celebrities. A.J. was male and used carbon monoxide poisoning, while the others were female and hung themselves. From these results, several explanations appear to be possible. Male celebrity suicide might induce less copycat suicide. Alternatively, males in the 30-39-year-old group might be less influenced by a celebrity's suicide. However, similar previous similar studies showed that male celebrity suicides specifically increased suicide rates in male groups ${ }^{14,17}$ and the 30-39-yearold group in the current study showed a high odds ratio in Period 4. Another factor could be the method. A.J. used carbon monoxide poisoning as a suicide method and during the Period 3, carbon monoxide poisoning was used much more than in the unaffected period, with an odds ratio of 3.671 (95\% CI: 2.622-5.140). We were able to determine two possible 


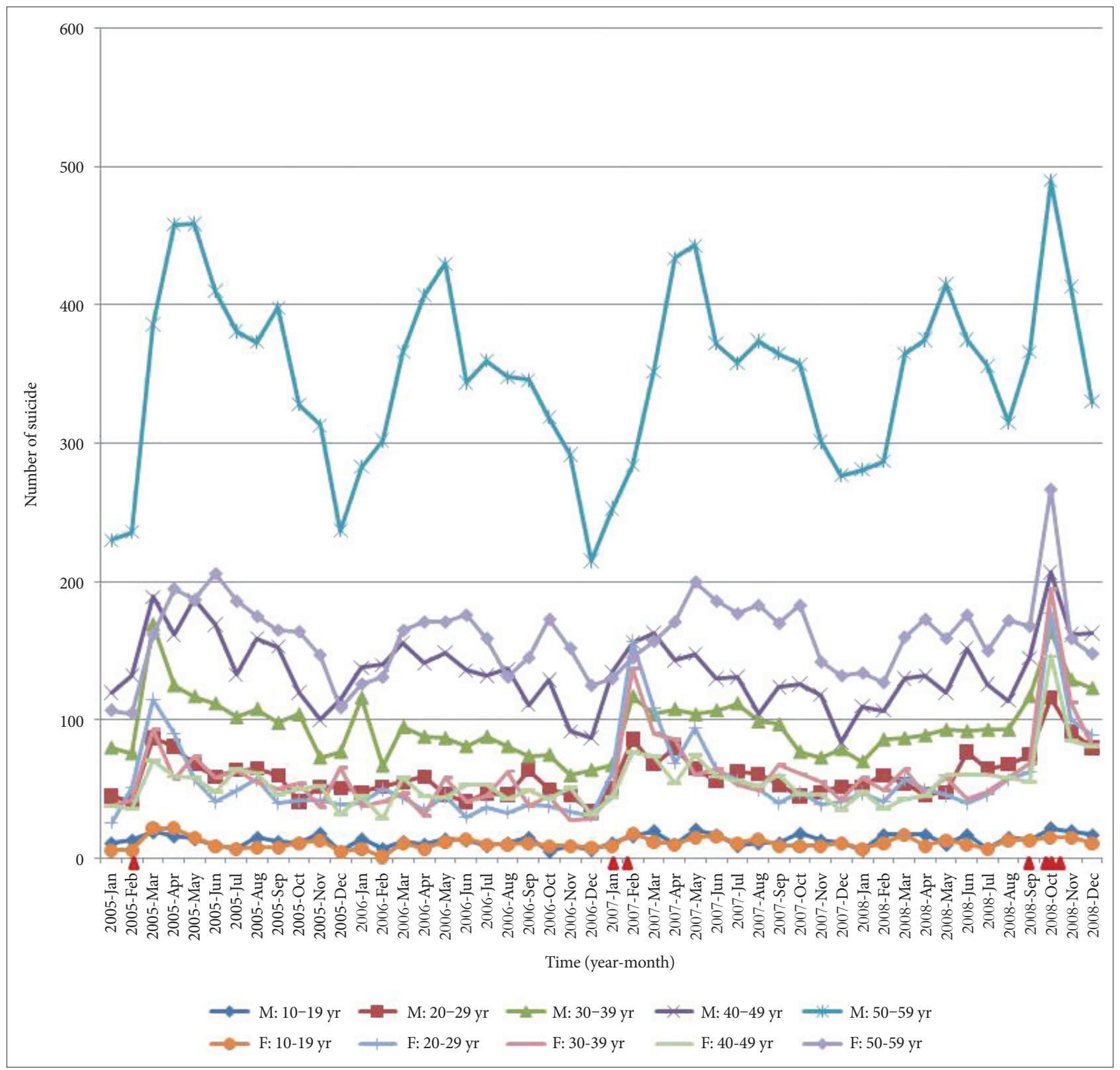

Figure 2. Monthly number of suicides by age and sex (South Korea, 2005-2008). Triangles represent points of celebrity suicides.

explanations related to the method. Primarily, given that carbon monoxide poisoning was a rare suicide method and less simple than hanging, A.J's death did not cause as many copycat suicides as the cases that involved suicide by hanging. The other possibility was that carbon monoxide poisoning had a fatality rate of about $2 \%$, which was much less than the $69 \%$ fatality rate for hanging; thus, there might have been many failed suicide attempts. ${ }^{22}$

Second, the risk of suicide induced by celebrity suicide increased gradually, excluding Period 3 (A.J.), which, as previously stated, had unique characteristics. This increase rose from $29.7 \%$ (95\% CI: 18.4-42.1\%) in 2005 (Period 1) to 42.2\% (95\% CI: 32.5-52.5\%) in 2007 (Period 2) and then to
95.4\% (95\% CI: 78.8-113.4\%) in 2008 (Period 4). Compared to the $17.4 \%$ (95\% CI: $4.0-32.6 \%$ ) increase observed in England and Wales in 1997, the 28\% (95\% CI: 2-59\%) increase in Hong Kong in 2003, and the 27\% increase in Taiwan in 2005, the increase in Korea were relatively high. ${ }^{18,27}$ One possible interpretation is that people were influenced by celebrity suicide more severely in Korea. The sharp increase could also be interpreted as a result of the cluster booster phenomenon. Celebrity suicide clusters that appeared to be copycat suicides were noted in our study. U.N. and J.D. committed suicide within 23 days of each other in 2005, and C.J, C.C., and K.J. all committed suicide within 6 days. Including A.J., four entertainment celebrities committed suicide within a month. 
Table 2. Adjusted relative risk of suicide during each period affected by an entertainment celebrity suicide (South Korea, 2005-2008)*

\begin{tabular}{ccr}
\hline Period (YYYY/MM/DD-YYYY/MM/DD) & Adjusted relative risk $\left(95 \%\right.$ confidence interval ${ }^{\dagger}$ & $\mathrm{p}$ \\
\hline Period 1 (2005/02/22-2005/03/21) & $1.297(1.184-1.421)$ & $<0.0001$ \\
Period 2 (2007/01/21-2007/03/09) & $1.422(1.325-1.525)$ & $<0.0001$ \\
Period 3 (2008/09/08-2008/10/01) & $1.146(1.037-1.266)$ & 0.0077 \\
Period 4 (2008/10/02-2008/10/29) & $1.954(1.788-2.134)$ & $<0.0001$ \\
\hline
\end{tabular}

*poisson time series autoregression model, adjusting for the effects of season, monthly variation, and unemployment rate, ${ }^{\dagger}$ for the previously described affected period, using the remainder of 2005-2008 as reference

Table 3. Adjusted odds ratio for the number of suicides in subgroups that match the celebrity during each period affected by an entertainment celebrity suicide (South Korea, 2005-2008)*

\begin{tabular}{|c|c|c|c|}
\hline Period & Subgroup & $\begin{array}{c}\text { Adjusted odds ratio } \\
(95 \% \text { confidence interval })^{\dagger}\end{array}$ & $\operatorname{Pr}>$ chiSq \\
\hline \multicolumn{4}{|l|}{ Sex } \\
\hline Period 1 & Female & $1.249(1.091-1.430)$ & 0.0013 \\
\hline Period 2 & Female & $1.866(1.635-2.129)$ & $<0.0001$ \\
\hline Period 3 & Male & $1.013(0.879-1.168)$ & 0.8585 \\
\hline Period 4 & Female & $1.553(1.400-1.721)$ & $<0.0001$ \\
\hline \multicolumn{4}{|l|}{ Age } \\
\hline Period 1 & $20-29$ & $1.452(1.210-1.741)$ & $<0.0001$ \\
\hline Period 2 & $20-29$ & $1.575(1.377-1.801)$ & $<0.0001$ \\
\hline Period 3 & $30-39$ & $1.111(0.929-1.328)$ & 0.2488 \\
\hline Period 4 & $30-39$ & $1.230(1.081-1.400)$ & $<0.0001$ \\
\hline \multicolumn{4}{|l|}{ Method } \\
\hline Period 1 & Hanging & $1.754(1.540-1.999)$ & $<0.0001$ \\
\hline Period 2 & Hanging & $1.866(1.684-2.607)$ & $<0.0001$ \\
\hline Period 3 & CO poisoning & $3.671(2.622-5.140)$ & $<0.0001$ \\
\hline Period 4 & Hanging & $2.334(2.095-2.599)$ & $<0.0001$ \\
\hline \multicolumn{4}{|l|}{ Sex $\times$ age } \\
\hline Period 1 & Female $\times 20-29$ & $1.742(1.378-2.204)$ & $<0.0001$ \\
\hline Period 2 & Female $\times 20-29$ & $2.351(1.991-2.777)$ & $<0.0001$ \\
\hline Period 3 & Male×30-39 & $1.106(0.890-1.375)$ & 0.3640 \\
\hline Period 4 & Female $\times 30-39$ & $1.697(1.430-2.014)$ & $<0.0001$ \\
\hline \multicolumn{4}{|l|}{ Sex $\times$ method } \\
\hline Period 1 & Female $\times$ Hanging & $1.829(1.547-2.162)$ & $<0.0001$ \\
\hline Period 2 & Female $\times$ Hanging & $2.503(2.224-2.817)$ & $<0.0001$ \\
\hline Period 3 & Male $\times \mathrm{CO}$ poisoning & $3.331(2.276-4.874)$ & $<0.0001$ \\
\hline Period 4 & Female $\times$ Hanging & $2.648(2.365-2.965)$ & $<0.0001$ \\
\hline \multicolumn{4}{|l|}{ Age $\times$ method } \\
\hline Period 1 & $20-29 \times$ Hanging & $2.449(1.982-3.025)$ & $<0.0001$ \\
\hline Period 2 & $20-29 \times$ Hanging & $2.515(2.161-2.927)$ & $<0.0001$ \\
\hline Period 3 & $30-39 \times \mathrm{CO}$ poisoning & $4.652(2.646-8.180)$ & $<0.0001$ \\
\hline Period 4 & $30-39 \times$ Hanging & $1.835(1.586-2.123)$ & $<0.0001$ \\
\hline \multicolumn{4}{|c|}{ Sex $\times$ age $\times$ method } \\
\hline Period 1 & Female $\times 20-29 \times$ Hanging & $2.438(1.966-3.136)$ & $<0.0001$ \\
\hline Period 2 & Female $\times 20-29 \times$ Hanging & $3.873(3.217-4.664)$ & $<0.0001$ \\
\hline Period 3 & Male $\times 30-39 \times$ CO poisoning & $3.948(2.037-7.650)$ & $<0.0001$ \\
\hline Period 4 & Female $\times 30-39 \times$ Hanging & $2.554(2.106-3.097)$ & $<0.0001$ \\
\hline
\end{tabular}

*logistic regression analysis model, adjusting for the effects of season, monthly variation, unemployment rate, sex, age and method, ${ }^{\prime}$ for the same subgroups matching each celebrity during the previously-described affected period, using the other subgroups and the remainder of $2005-2008$ as a reference 
We could assume that the second, third, and fourth suicides were copycat suicides of first suicide. The more celebrities that were involved, the more the copycat effect was induced. This cluster booster phenomenon was likely influenced considerably by the media. After the second celebrity's suicide in the cluster, the media re-focused on the first celebrity's suicide, and the subject "celebrity suicide" itself may likely be much more focused on single suicides. Additionally, some celebrities received considerably more media attention after committing suicide. For instance, in the cases of C.C. and K.J., who were less popular among the public, they were only reported on once or twice before their suicides; however, more than 25 reports were published after their deaths. People who had not even known their existence could focus on and discuss their suicides. All of these images constructed by the media had a greater impact on the public and on vulnerable people, leading to more copycat suicides. ${ }^{23,24}$

The differential identification theory might be able to account for our results that copycat suicide was induced among people who identified more with the celebrities. ${ }^{25}$ When people who are at suicide risk due to depression, feelings of worthlessness, or other mental illnesses, ${ }^{26}$ read a tragic story of a celebrity who is similar to themselves, they might be apt to identify with the celebrity more. The more they identified with the celebrities, the more permissive an attitude to suicide they would take, such that the suicide risk might be increased in this population. ${ }^{27}$

There were several limitations in our study. Although we set the affected period as 4 weeks, there has been debate about the suitability of the duration of this period. ${ }^{28,29}$ Analyzing the impact of suicide itself on a daily basis rather than in set affected periods would also be helpful in analyzing overlapping celebrity suicides. In addition, as this study was a population study, we could not conclusively determine that the people who seemed to be victims of the copycat effect were actually affected by these celebrity suicides. We also analyzed suicide deaths only and did not include suicide attempts. It has been reported that there are about 25 attempts for every successful suicide. ${ }^{30}$ In South Korea, in terms of suicide ideations, plans, and attempts, the lifetime prevalences were reported to be $15.2 \%, 3.3 \%$, and $3.2 \%$, respectively, which are all much higher than completed suicide. ${ }^{31}$ Furthermore, given that unplanned suicide attempts are associated with affective and alcohol use disorders, the copycat effect might be manifested as a suicide attempt in this vulnerable population. ${ }^{32}$ Consideration of people with entire suicidal behaviors would be needed to determine the authenticity of the copycat effect. Also, we did not analyze data related to the media reports, such as the number of media reports about each suicide, the duration of the media reports, and the quality of the me- dia reports, which could have a direct influence on copycat suicides. Further research will need to be conducted to address these issues.

After the period observed in this study, many celebrity suicides have occurred in South Korea, and it has also been inferred that many people have subsequently committed suicide due to the copycat effect. ${ }^{33}$ Though the Korean Association for Suicide Prevention suggested and distributed a "recommendation for media reports on suicide" in 2004, considerable sensational media coverage has still been reported. Stronger measures for better media reporting of suicides are needed. In addition, special efforts to prevent celebrity suicides themselves, such as educational programs targeting entertainment celebrities who start in South Korea, are thought to be a fundamental way of reducing the copycat effect.

\section{Acknowledgments}

We appreciate Dr. Wang Xiangdong, Regional Adviser in Mental Health and Control of Substance Abuse in World Health Organization Western Pacific Regional Office, who inspired us to start this research.

\section{REFERENCES}

1. Phillips DP. The influence of suggestion on suicide: substantive and theroretical implications of the Werther effect. Am Sociol Rev 1974; 39:340-354.

2. Stack S. Suicide in the media: a quantitative review of studies based on non-fictional stories. Suicide Life Threat Behav 2005;35:121-133.

3. Stack S. Celebrities and suicide: a taxonomy and analysis, 1948-1983. Am Sociol Rev 1987;52:401-412.

4. Kwon JW, Chun H, Cho SI. A closer look at the increase in suicide rates in South Korea from 1986-2005. BMC Public Health 2009;9:72.

5. WHO. Preventing Suicide: A Global Imperative. Geneva: World Health Organization; 2014.

6. OECD. "Suicides", in OECD. OECD Factbook 2013: Economic, Environmental and Social Statistics. Paris: OECD Publishing; 2013. Available at: http://dx.doi.org/10.1787/factbook-2013-97-en. Accessed August 3, 2015.

7. Veale J. South Koreans are Shaken by a Celebrity Suicide. TIME WORLD, 2008. Available at: http://www.time.com/time/world/article/0,8599,1847437,00.html. Accessed August 3, 2015.

8. Ji NJ, Lee WY, Noh MS, Yip PS. The impact of indiscriminate media coverage of a celebrity suicide on a society with a high suicide rate: epidemiological findings on copycat suicides from South Korea. J Affect Disord 2014;156:56-61.

9. Kim WJ, Song YJ, Namkoong K, Kim JM, Yoon HJ, Lee E. Does a copycat effect exist in the emergency department? Int J Psychiatry Med 2013;45:59-72.

10. Lee J, Lee WY, Hwang JS, Stack SJ. To what extent does the reporting behavior of the media regarding a celebrity suicide influence subsequent suicides in South Korea? Suicide Life Threat Behav 2014;44:457-472.

11. Myung W, Won HH, Fava M, Mischoulon D, Yeung A, Lee D, et al. Celebrity suicides and their differential influence on suicides in the general population: a national population-based study in Korea. Psychiatry Investig 2015;12:204-211.

12. Korean Statistical Information Service. Unemployment rate by gender/ age group. Statistics Korea. Available at: http://kosis.kr/eng/statisticsList/statisticsList_01List.jsp?vwcd=MT_ETITLE\&parmTabId=M_01 _01\#SubCont. Accessed August 3, 2015.

13. Hawton K, Harriss L, Simkin S, Juszczak E, Appleby L, McDonnell R, 
et al. Effect of death of Diana, princess of Wales on suicide and deliberate self-harm. Br J Psychiatry 2000;177:463-466.

14. Yip PS, Fu KW, Yang KC, Ip BY, Chan CL, Chen EY, et al. The effects of a celebrity suicide on suicide rates in Hong Kong. J Affect Disord 2006;93:245-252.

15. Cameron AC, Trivedi PK. Regression Analysis of Count Data. Cambridge: Cambridge University Press; 2013.

16. Chen YY, Liao SF, Teng PR, Tsai CW, Fan HF, Lee WC, et al. The impact of media reporting of the suicide of a singer on suicide rates in Taiwan. Soc Psychiatry Psychiatr Epidemiol 2012;47:215-221.

17. Cheng AT, Hawton K, Lee CT, Chen TH. The influence of media reporting of the suicide of a celebrity on suicide rates: a populationbased study. Int J Epidemiol 2007;36:1229-1234.

18. Casey P, Gemmell I, Hiroeh U, Fulwood C. Seasonal and socio-demographic predictors of suicide in Ireland: a 22 year study. J Affect Disord 2012;136:862-867.

19. Inoue K, Nishimura Y, Nishida A, Fukunaga T, Masaki M, Fujita Y, et al. Relationships between suicide and three economic factors in South Korea. Leg Med (Tokyo) 2010;12:100-101.

20. Tsai JF, Cho W. The secular trend of suicide rate and the socio-economic, media, and climatic factors in Taiwan, 1976-2009: a populationbased study. J Affect Disord 2011;129:270-274.

21. Choe SH. Web Rumors Tied to Korean Actress's Suicide. The New York Times, 2008. Available at: http://www.nytimes.com/2008/10/03/ world/asia/03iht-03actress.16656916.html. Accessed August 3, 2015.

22. Vyrostek SB, Annest JL, Ryan GW. Surveillance for fatal and nonfatal injuries-- United States, 2001. MMWR Surveill Summ 2004;53:1-57.

23. Kim R. Transgender commits suicide. The Korea Times, 2008. Available at: http://www.koreatimes.co.kr/www/news/nation/2011/04/117_32236. html. Accessed August 3, 2015

24. Park SS. Gay actor found dead in apparent suicide. The Korea Times,
2008. Available at: http://www.koreatimes.co.kr/www/news/nation/2011/04/117_32358.html. Accessed August 3, 2015

25. Stack S. Divorce, suicide, and the mass media: an analysis of differential identification, 1948-1980. J Marriage Fam 1990;52:553-560.

26. Jeon HJ, Park JI, Fava M, Mischoulon D, Sohn JH, Seong S, et al. Feelings of worthlessness, traumatic experience, and their comorbidity in relation to lifetime suicide attempt in community adults with major depressive disorder. J Affect Disord 2014;166:206-212.

27. Jeon HJ, Park JH, Shim EJ. Permissive attitude toward suicide and future intent in individuals with and without depression: results from a nationwide survey in Korea. J Nerv Ment Dis 2013;201:286-291.

28. Bollen KA, Phillips DP. Imitative suicides: a national study of the effects of television news stories. Am Sociol Rev 1982;47:802-809.

29. Fu KW, Yip PS. Estimating the risk for suicide following the suicide deaths of 3 Asian entertainment celebrities: a meta-analytic approach. J Clin Psychiatry 2009;70:869-878.

30. Drapeau C, McIntosh J. USA suicide 2013: Official final data. American Association of Suicidology, 2015. Available at: http://www.suicidology.org/Portals/14/docs/Resources/FactSheets/2013datapgsv2alt. pdf. Accessed August 3, 2015.

31. Jeon HJ, Lee JY, Lee YM, Hong JP, Won SH, Cho SJ, et al. Lifetime prevalence and correlates of suicidal ideation, plan, and single and multiple attempts in a Korean nationwide study. J Nerv Ment Dis 2010;198:643646.

32. Jeon HJ, Lee JY, Lee YM, Hong JP, Won SH, Cho SJ, et al. Unplanned versus planned suicide attempters, precipitants, methods, and an association with mental disorders in a Korea-based community sample. J Affect Disord 2010;127:274-280.

33. Kim J. FACTBOX - Chronology of South Korean celebrity suicides. 10Asia, 2010. Available at: http://www.asiae.co.kr/news/view.htm?sec= ent5\&idxno=2010070116055493284. Accessed August 3, 2015. 